\title{
Regulation of Biosynthesis of Syringolin A, a Pseudomonas syringae Virulence Factor Targeting the Host Proteasome
}

\author{
Christina Ramel, Nando Baechler, Michel Hildbrand, Martin Meyer, David Schädeli, and Robert Dudler \\ Institute of Plant Biology, University of Zurich, Zollikerstrasse 107, CH-8008 Zurich, Switzerland \\ Submitted 23 March 2012. Accepted 16 May 2012.
}

\begin{abstract}
Many strains of the phytopathogenic bacterium Pseudomonas syringae pv. syringae synthesize the virulence factor syringolin A, which irreversibly inactivates the eukaryotic proteasome. Syringolin $A$, a peptide derivative, is synthesized by a mixed nonribosomal peptide/polyketide synthetase encoded by five clustered genes, sylA to $s y l E$. Biosynthesis of syringolin A, previously shown to be dependent on the GacS/GacA two-component system, occurs in planta and in vitro but only under still culture conditions in a defined medium. Here, we show that the $s y l C$, sylD, and sylE genes of $P$. syringae pv. syringae B301D-R form an operon transcribed by promoter sequences located between the $s y l C D E$ operon and the $s y l B$ gene residing on opposite strands. Assays of overlapping $s y l B$ and sylCDE promoter deletions translationally fused to the lac $Z$ gene defined promoter sequences required for gene activity both in vitro and in planta. Activation of both promoters depended on the sylA gene encoding a helixturn-helix (HTH) LuxR-type transcription factor which was shown to directly bind to the promoters. Activity of the sylA gene, in turn, required a functional salA gene, which also encodes an HTH LuxR-type transcription factor. Furthermore, evidence is presented that acyl-homoserine lactone-mediated quorum-sensing regulation is not involved in syringolin A biosynthesis but that oxygen concentration appears to play a role.
\end{abstract}

Many strains of the phytopathogenic bacterium Pseudomonas syringae pv. syringae secrete syringolins, a family of closely related cyclic peptide derivatives, in planta and under suitable in vitro culture conditions (Wäspi et al. 1998a, 1999). Spray application of syringolin A, the predominant variant, onto powdery mildew-infected wheat and Arabidopsis results in large transcriptome changes and programmed cell death at infection sites (Michel et al. 2006; Wäspi et al. 2001). Syringolin A was also shown to be an important virulence factor in the interaction of $P$. syringae pv. syringae $\mathrm{B} 728 \mathrm{a}$ with bean (Phaseolus vulgaris) (Groll et al. 2008). Elucidation of syringolin A's mode of action revealed that it covalently binds to the active site residue of all three catalytic subunits of the eukaryotic proteasome by a novel mechanism, thereby irreversibly inhibiting proteasomal protein degradation (Groll et al. 2008).

Corresponding author: R. Dudler; Telephone: +41 4463482 52; Fax: +41 4463482 04; E-mail: rdudler@botinst.uzh.ch

*The $e$-Xtra logo stands for "electronic extra" and indicates that a supplementary table is published online.
Recently, experiments with bean and Arabidopsis thaliana revealed that proteasome inhibition by syringolin A suppresses the stomatal immune reaction and the salicylic acid-dependent host defense pathway (Schellenberg et al. 2010).

Syringolin A is a tripeptide derivative that consists of an Nterminal valine followed by the two nonproteinogenic amino acids 3,4-dehydrolysine and 5-methyl-4-amino-2-hexenoic acid, the latter two forming a 12-membered macrolactam ring structure. The N-terminal valine is linked by a urea moiety to the amino group of a second valine (Wäspi et al. 1998a). In minor variants, one or both valines can be substituted by isoleucine residues, and the 3,4-dehydrolysine by lysine (Wäspi et al. 1999). Syringolins are synthesized by a mixed nonribosomal peptide synthetase/polyketide synthase (NRPS/PKS) which is encoded by a gene cluster comprising five open reading frames (ORF) termed sylA to sylE (Amrein et al. 2004). These genes are sufficient to direct syringolin A biosynthesis when transferred to Pseudomonas strains lacking syringolin A biosynthesis genes (Ramel et al. 2009). The architecture of these genes and experimental evidence allowed researchers to postulate a biosynthesis model completely explaining syringolin A's structure (Amrein et al. 2004; Imker et al. 2009; Ramel et al. 2009). Whereas sylC and sylD encode NRPS and PKS modules of the syringolin A synthetase, the $s y l B$ gene is thought to be responsible for the desaturation of the 3,4-dehydrolysine residue (Amrein et al. 2004). The sylA gene encodes a helix-turn-helix (HTH) LuxR-type DNA-binding domain protein hypothesized to be a transcriptional regulator, whereas the $s y l E$ gene codes for a major facilitator superfamily protein postulated to represent the syringolin A exporter (Amrein et al. 2004).

The regulation of syringolin A biosynthesis appears to be complex. Syringolin A production was shown to be dependent on the lemA gene (Reimmann et al. 1995; Wäspi et al. 1998a) encoding the sensor part of the GacS/GacA two-component system, which controls many aspects of pathogenicity such as phytotoxin and protease production and lesion formation (Hrabak and Willis 1992; Rich et al. 1992, 1994). Syringolin A is produced in planta, even if bacteria are infiltrated into nonhost species, and in vitro under still culture conditions (Wäspi et al. 1998a) in a medium originally optimized for the production of the phytotoxin syringomycin (Gross 1985; Mo and Gross 1991a and b).

In order to elucidate the regulation of syringolin A biosynthesis, we demonstrate here that the $s y l C$, sylD, and $s y l E$ genes are transcribed as an operon and that the intergenic region between the $s y l B$ and $s y l C D E$ genes, which reside on opposite DNA strands, contains the promoters responsible for transcription of these genes. We show that the product of the sylA gene directly activates the $s y l B$ and $s y l C D E$ genes, and that the $s a l A$ 
gene, which also encodes an HTH LuxR-type DNA-binding domain protein (Kitten et al. 1998), is required for the activation of $s y l A$. In addition, we present evidence that the acylhomoserine lactone quorum-sensing (QS) system is not involved in syringolin A biosynthesis but that oxygen concentration appears to play a role.

\section{RESULTS}

The $s y l C$, sylD, and $s y l E$ genes form an operon.

The syringolin A gene cluster consists of the five ORF sylA to sylE (Amrein et al. 2004). The arrangement of the sylC, $s y l D$, and $s y l E$ genes suggests that they may be transcribed as an operon, likely regulated together by a promoter residing in the intergenic region between the $s y l B$ and $s y l C$ genes (Fig. 1A).

Amplification of the intergenic regions between $s y l C$, sylD, and sylE from RNA by reverse-transcriptase polymerase chain reaction (RT-PCR) indicated that these genes are indeed transcribed as a single polycistronic mRNA (Fig. 1B). This finding was corroborated by RNA gel-blot analysis with RNA extracted from the wild-type strain carrying the sylA overexpression construct pOEAC (Ramel et al. 2009) using sylC and sylE fragments as hybridization probes. Both the sylC and sylE gene fragments labeled a band corresponding to a large RNA of a size consistent with the $18 \mathrm{~kb}$ expected for a transcript encompassing the $s y l C$, sylD, and $s y l E$ ORF, which have a size of $3,984,12,570$, and 1,233 nucleotides, respectively (Fig. 1C). This result confirmed that these ORF are transcribed as an operon.

To identify promoter sequences expected to reside within the intergenic region between the $s y l B$ and $s y l C$ ORF, reporter genes were constructed in which the 221-bp intergenic sequence plus 18 and $5 \mathrm{bp}$ of the coding regions of the $s y l B$ and $s y l C$ genes, respectively, was fused in frame with the lacZ ORF of
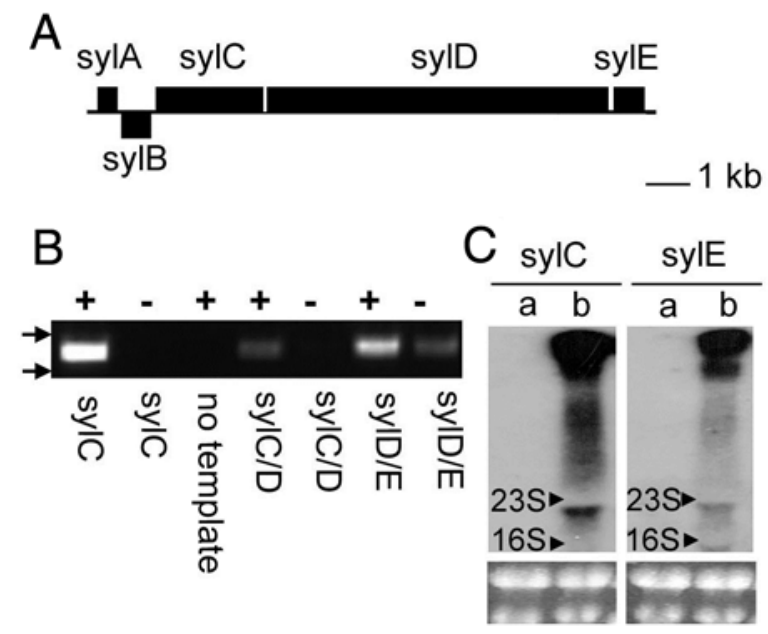

Fig. 1. SylC, sylD, and sylE are transcribed as an operon. A, Genomic region of Pseudomonas syringae pv. syringae B301D-R containing the sylA to sylE genes (accession number AJ548826). Boxes above and below the line denote open reading frames on the top and the bottom strand, respectively. B, Reverse-transcriptase polymerase chain reaction with primers amplifying a 359-bp sylC gene fragment or 368- and 378-bp fragments containing the $s y l C / D$ and $s y l D / E$ intergenic regions, respectively. Reactions did (+) or did not (-) contain reverse transcriptase. The arrows on the left denote the position of the 400-bp (upper) and 300-bp (lower) molecular weight markers. C, Top panels: autoradiogram of an RNA gel blot hybridized with an $s y l C$ and $s y l E$ probe, respectively. Positions of the $16 \mathrm{~S}$ and $23 \mathrm{~S}$ rRNAs are indicated. RNA was extracted from $P$. syringae pv. syringae B301D-R from which the complete syl gene cluster has been deleted (lane a) or from $P$. syringae pv. syringae B301D-R overexpressing the sylA gene (lane b). Bottom panels: ethidium bromide-stained gel.
pME6014 in both orientations (Schnider-Keel et al. 2000). These constructs were named psylBp-lacZ and psylCp-lacZ, respectively. We note that, in psylCp-lacZ, not the first ATG codon but an in-frame ATG codon encoding the seventh amino acid of the sylC ORF, as originally annotated by Amrein and associates (2004), represents the translational initiation codon of the $s y l C$ gene (see below). Translational lacZ fusions after the first ATG were completely inactive.

\section{The LuxR-type transcription factor SylA} is a positive regulator of the $s y l B$ and $s y l C$ promoters.

The sylA gene encodes a putative protein with an HTH LuxR-type DNA-binding domain. The location of the sylA gene and the fact that syringolin A production was abolished if the sylA gene was disrupted by plasmid insertion (Amrein et al. 2004) led to the hypothesis that the sylA gene product may be a positive regulator of the $s y l B$ and $s y l C D E$ transcriptional units. To verify this hypothesis, a markerless sylA deletion mutant $(\Delta$ sylA) was constructed and transformed with the reporter constructs. In this mutant, the activities of the $s y l B$ and the sylC promoters were strongly decreased as compared with the wild type (Table 1).

Next, we placed the sylA gene under the control of the $l a c Z$ promoter onto the $s y l B$ and $s y l C$ reporter plasmids, resulting in the sylA overexpression constructs pOEAB and pOEAC, respectively. $\beta$-Galactosidase ( $\beta$-gal) assays of the wild type and the $\Delta$ sylA mutant transformed with these constructs revealed a large increase of the $s y l B$ and $s y l C$ promoter activities compared with the reporter plasmids psylBp-lacZ and psylCp-lacZ in the wild-type background (Table 1). In addition, syringolin A concentrations of conditioned media from the former strains also increased with the same order of magnitude compared with the wild-type strain carrying the empty vector (data not shown). We conclude from these experiments that SylA is a positive regulator of syringolin A biosynthesis that directly or indirectly activates the $s y l B$ and $s y l C$ promoters.

Delimitation of essential $s y l B$ and $s y l C$ promoter regions.

To delimit sequences necessary for activity of the $s y l B$ and $s y l C$ promoters, overlapping deletions of the $s y l B$-sylC intergenic DNA fragment were prepared by PCR amplification (Fig. 2A; Supplementary Table S1 shows the primer sequences) that were translationally fused to the lac $Z$ reporter gene in pME6014. Results of $\beta$-gal assays with Pseudomonas syringae pv. syringae B301D-R strains transformed with these reporter plasmids and grown under still culture conditions are shown in Figure 3. For the $s y l B$ gene, fragments comprising 226 (full length), 153, 117, and $105 \mathrm{bp}$ upstream of the translation initiation were active to approximately the same extent (Fig. 3A, black columns), whereas fragments of $90,75,67$, and $57 \mathrm{bp}$ only led to basal activities (open columns). For the $s y l C$ gene, promoter fragments encompassing 239 (full length), 175, and $124 \mathrm{bp}$ of upstream sequence were active above basal levels

Table 1. Effect of $s y l A$ on $s y l B$ and $s y l C$ reporter gene activity

\begin{tabular}{lccll}
\hline Strain $^{\text {a }}$ & Reporter & $\boldsymbol{\beta}$-Gal (MU) & & Comment \\
\hline WT (psyBp and lacZ) & sylB & $705 \pm 37$ & $\ldots$ & \\
$\Delta$ sylA (psyBp and lacZ) & sylB & $96 \pm 20$ & $\ldots$ & \\
WT (psyCp and lacZ) & sylC & $1,194 \pm 108$ & $\ldots$ & \\
$\Delta$ sylA (psyCp and lacZ) & sylC & $106 \pm 6$ & $\ldots$ & \\
WT (pOEAB) & sylB & $6,960 \pm 149$ & sylA overexpression \\
$\Delta$ sylA (pOEAB) & sylB & $7,128 \pm 106$ & sylA overexpression \\
WT (pOEAC) & sylC & $7,923 \pm 249$ & sylA overexpression \\
$\Delta$ sylA (pOEAC) & sylC & $9,600 \pm 415$ & sylA overexpression \\
\hline
\end{tabular}

${ }^{\mathrm{a}} \mathrm{WT}=$ wild type.

b $\beta$-Galactosidase $(\beta$-Gal) activity. Means \pm standard error $(n>15)$ in Miller units (MU). 
(Fig. 3B, black columns), although activities seemed consistently to decrease with shorter fragment length. Fragments of $110,96,82$, and 68 bp resulted in basal activities (open columns). The shortest active $s y l B$ and $s y l C$ promoter fragments (105 and $124 \mathrm{bp}$, respectively) overlap for $8 \mathrm{bp}$ at their $5^{\prime}$ ends (Fig. 2A).

To complement these results from in vitro cultures, $\beta$-gal activity was also monitored in planta after infiltration of bacteria harboring reporter plasmids into leaves of Nicotiana benthamiana using a colorigenic substrate (Hull et al. 1996; Teeri et al. 1989). The results were consistent with the ones obtained from in vitro cultures and identified the 105-bp sylB and 124-bp sylC promoter fragments as the minimal fragments necessary for promoter activity in planta (Fig. 4A).

Analysis of the 221-bp intergenic region with the Virtual Footprint program (Munch et al. 2005) predicted putative imperfect dyad binding sites on both strands with scores (9.6 and 9.79) for the $P$. aeruginosa HTH LuxR-type response regulator RhlR near the ends of the shortest active $s y l B$ and $s y l C$ promoter fragments (Fig. 2A, boxed; the binding sequence logo is depicted in Fig. 2B). This putative binding site is present in all active fragments but absent or truncated in all $s y l B$ promoter fragments exhibiting basal activities. This holds true also for the sylC promoter, except for the shortest active deletion (124 bp of upstream sequence), where it is severely truncated (Fig. 2A). Intriguingly, analysis with the Virtual Footprint program of this deletion clone, including the neighboring vector sequences, revealed that, by chance, a good RhlR binding site with a score of 10.68 was recreated around the EcoRI cloning site into which this deletion fragment was cloned (Fig. 2A), thus suggesting that this putative binding site may also be important for $s y l C$ transcriptional activation.

\section{A maltose-binding protein-SylA fusion protein binds to $s y l B / s y l C$ promoter fragments.}

In order to determine whether the SylA positive regulator binds directly to the $s y l B$ and $s y l C$ promoter fragments, maltosebinding protein (MBP)-SylA fusion proteins were generated. The sylA gene was amplified by PCR, cloned in frame into the vectors pMal-c2X (for expression in Escherichia coli) and pMEKm12 (a derivative of pMal-c2X) for expression in $P$. $s y$ ringae (Lu et al. 2002b) to yield pMalSylA and pMEKmSylA, respectively. The recombinant plasmids were transformed into E. coli $\mathrm{DH} 10 \mathrm{~B}$ and $P$. syringae pv. syringae $\mathrm{B} 301 \mathrm{D}-\mathrm{R}$.

MBP-tagged proteins were purified from extracts of both organisms by maltose-affinity chromatography and subjected to gel-blot analysis using an anti-MBP antibody, which revealed bands of approximately $70 \mathrm{kDa}$, the expected size of the MBPSylA fusion protein (data not shown). To test whether the MBPSylA fusion protein was functional in vivo, pMEKmSylA was transformed into the $P$. syringae pv. syringae B301D-R $\Delta$ sylA deletion mutant and tested for complementation of the syringolin A-negative phenotype using a rice infiltration assay. We have previously established that infiltration of syringolin A or syringolin A-synthesizing bacteria into rice leaves results in the accumulation of Pir7b transcripts, whereas syringolin Anegative strains or mutants do not induce this gene. (Hassa et al. 2000; Ramel et al. 2009; Wäspi et al. 1998b, 1999). Gelblot analysis of RNA from infiltrated rice leaves revealed that transformation of the $\triangle$ sylA mutant with pMEKmSylA complemented the mutant and led to strong Pir $7 b$ transcript accumulation, whereas no Pir7b transcripts were detected in leaves infiltrated with the $\triangle$ sylA mutant with or without the empty control vector (Fig. 5A). This result confirmed that the MBPSylA fusion protein was functional in vivo.
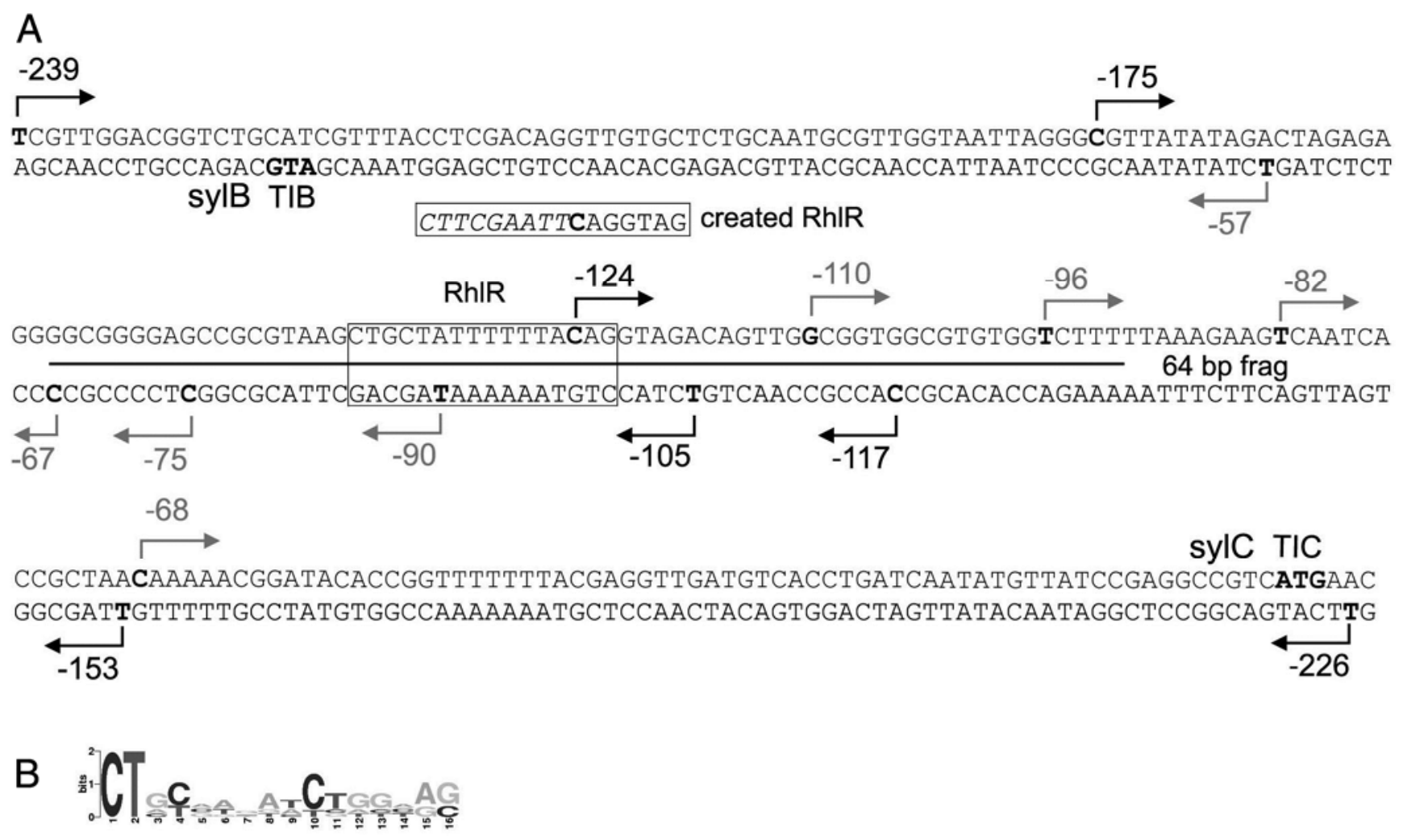

Fig. 2. A, Intergenic region between the $s y l B$ and $s y l C$ genes. Translation initiation codons of the $s y l B$ (TIB, bottom strand) and $s y l C$ (TIC, top strand) genes are shown in bold letters. Positions of promoter deletion breakpoints relative to the respective translational initiation codon are indicated with negative numbers above $(s y l C)$ or below $(s y l B)$ arrows. Fragments with background promoter activities are indicated with gray arrows, fragments with activities above background with black ones. A 64-bp-long subfragment used in MDAE experiments is marked with a bar between the DNA strands. The RhIR-like binding site residing within the 64-bp fragment as well as the one recreated by cloning the -124-bp fragment into the EcoRI cloning site (italics) are boxed. B, RhlR binding-sequence logo. 
Binding of the MBP-SylA fusion protein to $s y l B / s y l C$ promoter fragments was examined using a magnetic DNA affinity enrichment (MDAE) approach. A 244-bp fragment containing the intergenic region between the $s y l B$ and $s y l C$ genes as well as 18 and $5 \mathrm{bp}$ of the $s y l B$ and $s y l C$ ORF was amplified by PCR using a biotinylated primer. As a negative control, a biotinylated internal 120-bp fragment of the sylC coding region was generated. The purified DNA fragments were immobilized on streptavidin-coated magnetic beads, which were then incubated with crude protein extracts from $P$. syringae pv. syringae B301D-R, E. coli expressing the MBP-SylA fusion protein, or MBP from the empty vector alone. Bound proteins were eluted and subjected to gel-blot analysis using MBP-specific antibodies. A band with the expected size of the fusion protein of approximately $70 \mathrm{kDA}$ was observed with the $s y l B / s y l C$ promoter probe but not with the negative control probe (Fig. 5B). Extracts from bacteria carrying the empty vector producing $\mathrm{MBP}$ alone $(51 \mathrm{kDa})$ resulted sometimes in a faint background band in the expected size range. Next, a 64-bp-long subfragment (Fig. 2A, underlined) encompassing the sequence upstream of position -66 relative to the $s y l B$ gene and upstream of -91 relative to the sylC gene, and which contains the putative RhlRlike binding site, was tested in MDAE experiments. MBP-SylA bound to this fragment as well (Fig. 5B, right panel). Identical results were obtained with protein extracts from $P$. syringae pv. syringae B301D-R and E. coli harboring the respective MBP:: SylA expression plasmids. These results strongly suggest that SylA is directly activating the $s y l B$ and $s y l C$ genes.

We also assayed fragments corresponding to the $-105,-90$, and -75 sylB promoter deletions. Although the -105 sylB promoter fragment bound the MBP::SylA fusion protein, the -90
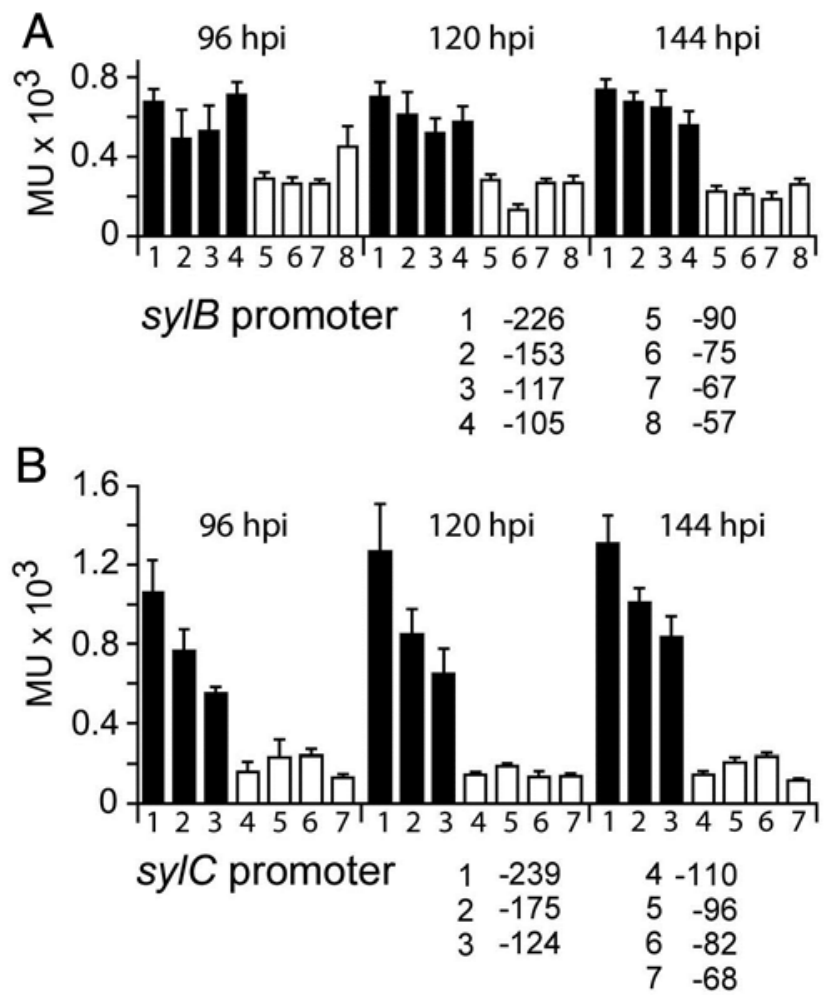

Fig. 3. Promoter activities of $\mathbf{A}, s y l B$ and $\mathbf{B}, s y l C$ deletion fragments. Open bars indicate fragments resulting in background activity and black bars indicate fragments with activities above background. Means of data points measured at three representative culture time points $(96,120$, and $144 \mathrm{~h}$ post inoculation [hpi]), each in 6 to 11 replicates, are given in Miller units (MU). Error bars indicate the standard error of the mean. Promoter fragments of the $s y l B$ and the $s y l C$ genes indicated for the 96-h time point apply analogously to the other time points. fragment (Fig. 5C, left panel) and the -75 fragment did not. This result is in agreement with the results from the promoter activity assays (Fig. 3A) and further suggests that the putative RhlR-like binding element, which is present in the -105 deletion but severely truncated in the -90 deletion (Fig. 2A), is important for $s y l B$ activation by the $s y l A$ gene product. The corresponding results with $s y l C$ deletion fragments revealed that the -124 deletion fragment only weakly bound the MBP::SylA fusion protein, whereas the -110 fragment weakly bound the fusion protein equally as well as the MBP protein alone (i.e., unspecifically) (Fig. 5C, right panel). Results with the -95 and -82 fragments were similar to those obtained with the -110 deletion.

SalA is an upstream activator of syringolin A biosynthesis.

First, we examined the activity of the sylA promoter by constructing an sylA::lacZ translational fusion gene (psylAp-lacZ) that encompassed the $445 \mathrm{bp}$ between the sylA translation initiation codon and the next upstream gene (which is highly conserved in $P$. syringae strains that lack a syringolin synthetase gene cluster, such as $P$. syringae pv. tomato DC3000 and $P$. syringae pv. phaseolicola) and the first 86 bp of the sylA ORF. $\beta$-Gal assays of the wild type transformed with psylAp-lacZ and grown under still culture conditions showed an activity of approximately 300 Miller units (MU), whereas the same construct in the $\Delta$ sylA background led to an approximately $50 \%$ higher activity (Table 2). Therefore, we checked whether this might indicate negative feedback control of SylA on its own gene promoter by placing the sylA gene under the control of the lac $Z$ promoter onto psylAp-lacZ to yield pOEAA. However, $\beta$-gal assays of the B301D-R wild-type strain carrying pOEAA exhibited activities similar to those carrying psylAplacZ (data not shown), thus not confirming the existence of a negative feedback loop.

Evidence from a microarray hybridization experiment reported in the literature ( $\mathrm{Lu}$ et al. 2005) suggested that the sylD gene belonged to the regulon controlled by the HTH LuxR-type transcription factor SalA, which was reported to positively regulate syringomycin biosynthesis (Lu et al. 2002a; Wang et al. 2006). Therefore, we tested whether SalA was also involved in syringolin A biosynthesis. Thus, psylAp-lacZ, psylBp-lacZ, and psylCp-lacZ reporter plasmids were transformed into the salA transposon insertion mutant DSL7 (Lu et al. 2002a) and $\beta$-gal activities were determined. The activities of the $s y l B$ and $s y l C$ promoters were strongly decreased in the salA mutant compared with the wild type (Table 2), indicating that the salA gene was necessary for expression of $s y l B$ and $s y l C$. Overexpression of sylA (using plasmid pOEAB and pOEAC) in the salA mutant background led to a dramatic increase of the $s y l C$ and $s y l B$ reporter, indicating that salA acts upstream of sylA. Consistent with this, syringolin A accumulation in conditioned media of the salA insertion mutant DSL7 was abolished but was restored by overexpression of $s y l A$ in this mutant (data not shown).

The salA gene under the control of the lacZ promoter was inserted into the psylAp-lacZ, psylBp-lacZ, and psylCp-lacZ reporter plasmids to yield pOESalAA, pOESalAB, and pOESalAC, respectively. When transformed into the $\Delta$ sylA mutant, pOESalAB and pOESalAC led to $\beta$-gal activities similarly low to those of psylBp-lacZ and psylCp-lacZ in the same genetic background, showing that overexpression of salA had no effect on the $s y l B$ and $s y l C$ promoters in the $\Delta$ sylA background (data not shown). In contrast, overexpression of salA in wild-type or salA-mutant bacteria transformed with pOESalAA consistently increased the activity of the sylA promoter approximately two- to threefold above the wild-type levels of approximately $300 \mathrm{MU}$, while the sylA reporter construct psylAp-lacZ led to $\beta$-gal activities of $172 \mathrm{MU}$ in the salA mutant background (Table 2). The sylA reporter plasmid psylAp-lacZ in wild-type 
bacteria led to blue staining of colonies in $N$. benthamiana, whereas no staining was detected in plants infiltrated with the salA mutant DSL7 carrying psylAp-lacZ (Fig. 4B).

These findings suggest that SalA directly or indirectly activates the $s y l A$ gene, whose product then activates the $s y l B$ and $s y l C$ genes. Next, we tested whether SalA directly binds to the

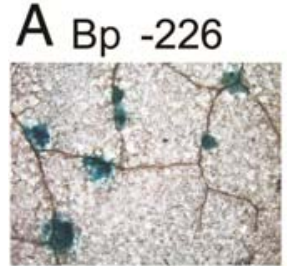

Cp -239

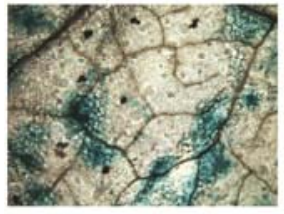

$\mathrm{B}$
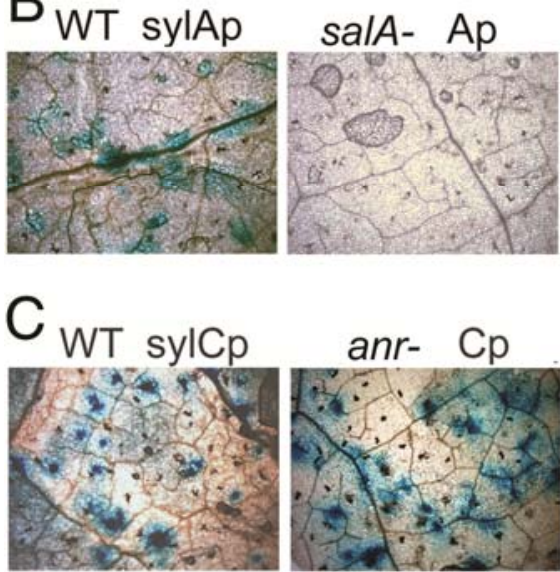

Fig. 4. Qualitative $\beta$-galactosidase activity staining of bacteria carrying promoter-lacZ fusions in leaves of Nicotiana benthamiana. Leaves were infiltrated with Pseudomonas syringae pv. syringae B301D-R at $10^{5}$ $\mathrm{CFU} / \mathrm{ml}$ carrying the indicated promoter-reporter constructs. Leaves were stained with 5-bromo-4-chloro-3-indolyl-beta-D-galactopyranoside after 72 to $96 \mathrm{~h}$. A, Leaves with bacteria carrying $s y l B(\mathrm{Bp})$ and $s y l C$ (Cp) promoter deletion reporter constructs were stained for equal amounts of time. B, $N$. benthamiana leaves infiltrated with wild-type (left panel) and salAmutant bacteria (right panel) harboring the psylAp-lacZ reporter plasmid. C, $N$. benthamiana leaves infiltrated with wild-type (WT) and Psyl3425ortholog (anr homolog)-negative bacteria carrying a full-length sylC::lacZ reporter construct stained for the same amount of time.
sylA promoter region using MDAE. The salA gene was cloned into pMEKm12 as a translational fusion to MBP, resulting in pMEKmSalA. This plasmid complemented the salA mutant DSL7 with regard to syringolin A production as monitored by Pir $7 b$ transcript accumulation upon infiltration of transformed bacteria into rice leaves, thus confirming that the MBP-SalA fusion protein was functional in vivo (Fig. 5A). However, no binding of MBP-SalA to the putative sylA promoter fragment

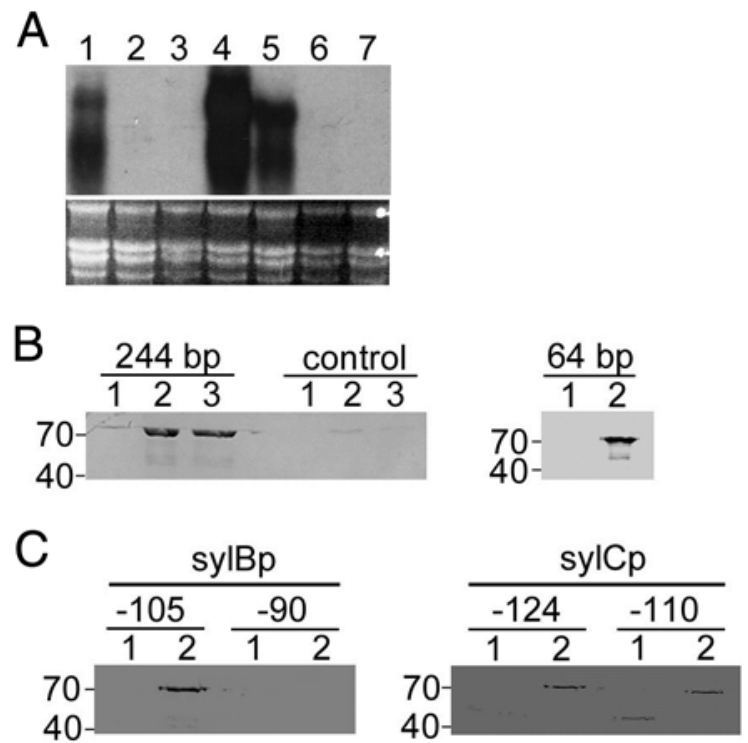

Fig. 5. Promoter binding assays with maltose-binding protein (MBP)-SylA and MBP-SalA fusion proteins. A, RNA gel-blot analysis of Pir $7 b$ transcript accumulation in rice leaves $16 \mathrm{~h}$ after infiltration of the wild-type Pseudomonas syringae pv. syringae B301D-R strain (lane 1), the $\Delta$ sylA mutant (lane 2 ), the $\Delta$ sylA mutant containing the empty vector pMEKm12 (lane 3), the $\Delta$ sylA mutant complemented with pMEKmSylA (lane 4), the salA insertion mutant DSL7 complemented with pMEKmSalA (lane 5), DSL7 containing the empty vector pMEKm12 (lane 6), and DSL7 (lane 7). Top panel: autoradiogram; bottom panel: ethidium-bromide-stained gel before blotting. The gel blot was probed with a radiolabeled Pir $7 b$ cDNA probe. B, Gel-blot analysis of protein eluates after magnetic DNA affinity enrichment (MDAE) using an MBP-specific antibody for immunodetection. Left panel: a 244-bp sylB/sylC promoter fragment or a 120-bp control fragment derived from the sylC coding region was bound to magnetic beads and incubated with extracts of $P$. syringae pv. syringae B301D-R carrying the empty vector (lane 1), MBP-SylA encoding pMEKmSylA (lane 2), and a 1:1 mixture of extracts from bacteria carrying pMEKmSylA or pMEKmSalA, respectively (lane 3). Right panel: MDAE with extracts from Escherichia coli carrying the empty vector (lane 1) or pMalSylA (lane 2) using a 64-bp subfragment. C, MDAE with $E$. coli extracts (lane 1, empty vector; lane 2, pMalSylA) using the indicated $s y l B$ (left panel) and $s y l C$ (right panel) promoter deletion fragments. The position and size in $\mathrm{kDa}$ of marker proteins is indicated on the left of panels in $\mathrm{B}$ and $\mathrm{C}$.

Table 2. Effect of salA on $s y l A, s y l B$, and $s y l C$ reporter gene activity

\begin{tabular}{|c|c|c|c|}
\hline Strain $^{a}$ & Reporter & $\beta$-Galactosidase activity ${ }^{b}$ & Comment \\
\hline WT (psylAp-lacZ) & sylA & $299 \pm 28$ & $\ldots$ \\
\hline$\Delta$ sylA (psylAp-lacZ) & sylA & $445 \pm 25$ & $\ldots$ \\
\hline WT (psylBp-lacZ) & sylB & $763 \pm 59$ & $n=9$ \\
\hline WT (psylCp-lacZ) & sylC & $1,237 \pm 33$ & $n=9$ \\
\hline DSL7 (psylBp-lacZ) & sylB & $76 \pm 9$ & salA mutant, $n=9$ \\
\hline DSL7 (psylCp-lacZ) & sylC & $209 \pm 14$ & salA mutant, $n=9$ \\
\hline DSL7 (pOEAB) & sylB & $7,778 \pm 218$ & salA mutant, sylA overexpression \\
\hline DSL7 (pOEAC) & sylC & $6,717 \pm 340$ & salA mutant, sylA overexpression \\
\hline WT (pOESalAA) & sylA & $761 \pm 41$ & salA overexpression \\
\hline DSL7 (pOESalAA) & sylA & $592 \pm 35$ & salA mutant, salA overexpression \\
\hline DSL7 (psylAp-lacZ) & sylA & $172 \pm 16$ & salA mutant \\
\hline
\end{tabular}

\footnotetext{
${ }^{\mathrm{a}} \mathrm{WT}=$ wild type.

${ }^{\mathrm{b}}$ Means \pm standard error ( $n>15$, except stated otherwise) in Miller units (MU).
} 
encompassing $445 \mathrm{bp}$ of sequence upstream of the sylA translation initiation codon and the first $86 \mathrm{bp}$ of the coding region was observed (data not shown). Binding to this fragment was also not observed after incubation with a 1:1 mixture of extracts containing MBP-SalA and MBP-SylA, respectively.

Because these results may indicate that the action of SalA on the sylA gene is indirect, we considered two other genes encoding HTH LuxR-type regulatory proteins, $s y r F$ and $s y r G$, as candidates possibly involved in syl gene regulation. $S y r F$ was reported to be directly activated by the SalA regulator and to activate, in turn, genes controlling syringomycin biosynthesis (Wang et al. 2006). SyrG is physically located adjacent to the salA gene and was reported to exhibit a twofold reduced expression level in an salA mutant. In addition, an $s y r G$-negative mutant exhibited reduced virulence on cherry fruits ( $\mathrm{Lu}$ et al. 2002a).

Thus, we generated $s y r F$ and $s y r G$ insertion mutants $\left(\mathrm{SyrF}_{-}\right.$ KO and SyrG_KO) in which the HTH LuxR-type DNA-binding domains of the putative gene products were interrupted. Upon transformation of the sylA and $s y l C$ reporter plasmids psylAplacZ and psylCp-lacZ into these mutants, $\beta$-gal activities similar to those in the wild type carrying the same plasmids were observed. Furthermore, rice infiltration assays with the $s y r F$ and $\operatorname{syr} G$ mutants exhibited wild-type Pir7b transcript levels as determined by RNA gel-blot analysis (data not shown). Thus, there is no evidence that $s y r F$ and $s y r G$ play a role in the regulation of syringolin A biosynthesis.

\section{Why does syringolin A accumulate in still but not in shaken cultures?}

Syringolin A can be isolated from conditioned media of $P$. syringae pv. syringae B301D-R grown under still culture conditions in $\mathrm{SRM}_{\mathrm{AF}}$ minimal medium (Wäspi et al. 1998a). Typically, 20 to $40 \mathrm{mg} /$ liter can be obtained after 7 to 10 days at $28^{\circ} \mathrm{C}$. In conditioned rich media (shaken and unshaken) or in shaken $\mathrm{SRM}_{\mathrm{AF}}$ cultures, syringolin A accumulates only to concentrations barely detectable by direct high-performance liquid chromatography (HPLC) analysis ( $<2 \mathrm{mg} / \mathrm{liter})$. Overexpression of the plasmid-borne sylA gene under the control of the lacZ promoter results in greatly increased syringolin A production in both still and shaken $\mathrm{SRM}_{\mathrm{AF}}$ cultures (typically 200 to 400 $\mathrm{mg} / \mathrm{liter}$ ). Correspondingly, sylA-overexpressing sylB::lacZ and sylC::lacZ reporter plasmids (pOEAB and pOEAC) resulted in high $\beta$-gal activities in shaken cultures, in contrast to psylBplacZ and psylCp-lacZ not overexpressing sylA (data not shown). One obvious difference between still and shaken culture conditions is the cell density reached. Typically, in still cultures, a plateau at an optical density at $600 \mathrm{~nm}\left(\mathrm{OD}_{600}\right)$ of 0.4 to 0.5 is reached after 3 to 4 days of growth at $28^{\circ} \mathrm{C}$ which is maintained until day 6 or 7 but declines thereafter. Because shaken cultures in $\mathrm{SRM}_{\mathrm{AF}}$ reach much higher cell densities (up to an $\mathrm{OD}_{600}$ of 4 after 4 days, and declining thereafter) and are much better aerated, we considered the possibility that syringolin A production might be either under negative QS control or inhibited by high oxygen concentration.

To test the first possibility, a markerless QS-negative mutant was constructed in $P$. syringae pv. syringae B301D-R, in which the orthologs of the adjacent ahlI autoinducer and $a h l R$ regulator genes of the closely related $P$. syringae pv. syringae B728a strain (Quinones et al. 2004) were deleted. Transformation of the $s y l B$ and $s y l C$ reporter plasmids psylBp-lacZ and psylCp-lacZ into this mutant revealed reporter gene activities not significantly different from those observed in the wild-type background under both still and shaken $\mathrm{SRM}_{\mathrm{AF}}$ cultures (data not shown). In addition, HPLC analysis of conditioned media from mutant and wild-type cultures contained similar syringolin A concentrations under all conditions (not shown). Thus, we conclude that syringolin A biosynthesis is not dependent on the ahll/ahlR QS system.

To examine the dependency of syringolin A production in vitro on oxygen concentration, sylC reporter activities (psylCplacZ in the $P$. syringae pv. syringae B301D-R wild type) were compared in shaken $\mathrm{SRM}_{\mathrm{AF}}$ cultures under normal and low oxygen conditions. Cultures were grown for $64 \mathrm{~h}$ under normal shaken conditions (i.e., culture flasks were capped with a lid allowing gas exchange). Thereafter, half of the culture flasks were flushed with $\mathrm{N}_{2}$ and sealed with parafilm to reduce gas exchange. All cultures were then shaken for another $46 \mathrm{~h}$. sylC::lacZ reporter activity increased significantly upon oxygen limitation (Fig. 6), indicating that oxygen concentration does play a role in the regulation of syringolin A biosynthesis.

A well-known regulator of responses to limiting oxygen concentrations is the E. coli Fnr protein and its P. aeruginosa homologue, Anr (Blumer and Haas 2000; Green et al. 2009; Sawers 1999). Under anaerobic conditions, Fnr forms a dimer that binds to DNA and can either activate or repress genes (Bauer et al. 1999; Melville and Gunsalus 1996). The only close homologue of Anr in P. syringae pv. syringae $\mathrm{B} 728 \mathrm{a}$ is YP_236495 (86\% identity and 94\% similarity) encoded by Psyr_3425 (GeneID 3368952). In order to examine the role of the Psyr_3425 ortholog in the regulation of syringolin A biosynthesis, a markerless deletion mutant was generated in the $P$. syringae pv. syringae B301D-R background, which then was transformed with the psylCp-lacZ and psylAp-lacZ reporter genes. Reporter activities of the respective plasmids in the mutant background were not significantly different from those measured in the wild-type background under both still and shaken culture conditions (data not shown). Furthermore, infiltration of wild-type and mutant strains into $N$. benthamiana leaves led to indistinguishable $\beta$-gal activity staining (Fig. 4C). In addition, both the wild type and the Psyr_3425-negative strains led to essentially the same Pir $7 b$ transcript levels upon infiltration into rice leaves. In summary, these results indicate that the Anr ortholog of $P$. syringae pv. syringae B301D-R does not play a role in the regulation of syringolin A biosynthesis.

\section{DISCUSSION}

Syringolin A biosynthesis can be conferred to the saprophytic $P$. putida by transformation with a cosmid harboring the

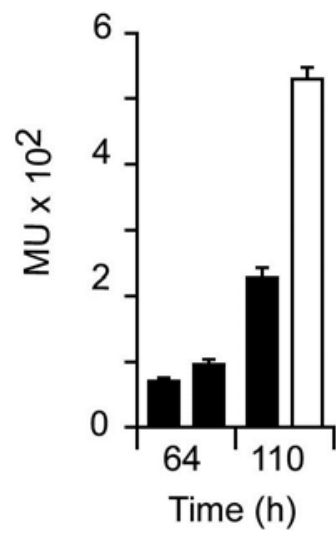

Fig. 6. Effect of oxygen concentration on sylC::lacZ reporter activity. Promoter activities were measured in Pseudomonas syringae pv. syringae B301D-R bacteria transformed with the psylCp-lacZ reporter construct. Cultures were first shaken for $64 \mathrm{~h}$ under aerated conditions. Then, oxygen was excluded from half of the cultures for another $46 \mathrm{~h}$ of shaking incubation (open bar), while the other half was shaken under aerated conditions (black bar). Average $\beta$-galactosidase activities in Miller units (MU) are given $(n=5)$. Error bars indicate the standard error of the mean. 
sylA-E gene cluster, indicating that no other specific genes are necessary (Ramel et al. 2009). Here, we presented evidence that $s y l C$, $s y l D$, and $s y l E$ form an operon. The activity of the sylCDE operon and the $s y l B$ gene on the opposite strand depends on the sylA gene and is greatly increased upon overexpression of the latter.

Overlapping deletions of the $s y l B / s y l C$ intergenic region allowed us to delimit minimal promoter fragments necessary to drive sylB::lacZ and sylC::lacZ reporter genes. The 226-bp fulllength $s y l B$ promoter (comprising a 221-bp intergenic DNA and a 5-bp sylC coding region) translationally fused to the $l a c Z$ gene resulted in an activity of approximately $700 \mathrm{MU}$. Essentially the same activities were also observed with the shorter fragments of 153,117 , and $105 \mathrm{bp}$. Shorter fragments of 90, 75, 67, and $57 \mathrm{bp}$ resulted in the same basal activity of approximately 200 to 300 MU, suggesting that the sequence between 105 and 90 bp contains elements important for promoter activity. These results were corroborated in planta upon infiltration of bacteria harboring these reporter constructs. Blue colonies inside the leaves appeared only with promoter deletions shown to be active in in vitro cultures, whereas no blue staining was detected with the reporter genes resulting in basal activities in vitro. This 15-bp region overlaps with a putative binding site for $P$. aeruginosa RhlR, the HTH-LuxR-type response regulator of a QS system in $P$. aeruginosa from position -100 to -85 relative to the $s y l B$ translational start site $\left(5^{\prime}\right.$-CTGTAAAAAATAGCAG on the $s y l B$ strand). Because SylA also exhibits a putative HTH LuxR-type DNA binding domain, it seems likely that this site is important for $s y l B$ gene activation. Indeed, this element $\left(5^{\prime}\right.$-CTGCTATT TTTTACAG on the $s y l C$ coding strand) appears also to be essential for $s y l C$ promoter activity. Although the shortest active sylC promoter deletion (124 bp of upstream sequence) contained only a severely truncated version, a new high-scoring putative binding site was fortuitously created together with a flanking vector sequence, which likely explains the activity of this fragment in vitro and in planta. These data are essentially in agreement with the MDAE experiments using promoter fragments and protein extracts from $E$. coli and $P$. syringae pv. syringae B301D-R which produce an MBP::SylA fusion protein. It is worthwhile to mention that all our efforts to perform MDAE experiments using affinity-purified MBP::SylA proteins, or to perform electrophoretic mobility shift assays with them, remained unsuccessful, which may indicate that either the MBP::SylA fusion protein is instable or binding only occurs in the presence of one or more additional factors which, however, would have to be present in extracts of both $E$. coli and $P$. syringae pv. syringae B301D-R.

Whereas the results of the deletion analysis suggest that, apart from the small region containing the RhlR-like binding motif, no other upstream sequence element is important for sylB transcription, the consistently higher activity of the 239bp (full-length) sylC promoter as compared with the -175 and -124 deletions (Fig. 2A) suggests that other sequence elements enhancing $s y l C$ transcriptional activity reside between positions -239 and -124 . Virtual Footprint analysis revealed putative $P$. aeruginosa integration host factor (IHF) binding sites (5'-CAATGCGT between -195 and -188 on the sylC coding strand, and 5'-CAACGCAT between -186 and -193 on the bottom strand relative to the $s y l C$ translation initiation codon) as the only notable feature we observed in this region. IHF can induce DNA bends (U-turns) at its binding site and is known to influence transcription (Dillon and Dorman 2010; Huo et al. 2009; Macchi et al. 2003). It remains presently unknown if these sites play a role in $s y l C$ transcriptional regulation.

We have previously established that syringolin A biosynthesis is controlled by the GacS/GacA two-component system and is abolished in a $\operatorname{gacS}$ (formerly designated lemA) mutant
(Reimmann et al. 1995; Wäspi et al. 1998a). The GacS/GacA global regulatory system has been found in numerous bacteria, including plant pathogens, where it was shown to control a plethora of phenotypes, among them pathogenicity, virulence, toxin production, and ecological fitness (Chatterjee et al. 2003; Heeb and Haas 2001; Hirano and Upper 2000; Hirano et al. 1997; Hrabak and Willis 1992, 1993; Willis et al. 1990). In the bean pathogen $P$. syringae pv. syringae B728a, some of the phenotypes observed in a gacS mutant, including loss of syringomycin production and lesion formation, could be restored by overexpressing the salA gene, whose expression was shown to depend on the GacS/GacA system (Kitten et al. 1998).

Here, we showed that syringolin A biosynthesis also is mediated by the salA gene product. Inactivation of salA resulted in negligible syringolin A production in in vitro cultures and to only basal activity of the $s y l B:: l a c Z$ and $s y l C:: l a c Z$ reporter genes. SalA acts upstream of sylA in the regulatory cascade, because overexpression of $s y l A$ in the salA mutant resulted in very high activities of the $s y l B:: l a c Z$ and $s y l C:: l a c Z$ reporter genes. The moderate sylA::lacZ reporter activity observed in the wild type was reduced to approximately $50 \%$ in in vitro cultures of the salA mutant whereas, in planta, no blue staining was observed. In contrast, overexpression of salA led to a two- to threefold increase of the sylA::lacZ reporter activity above wild-type levels, indicating that SalA directly or indirectly activates the sylA gene. We were not able to demonstrate direct binding of a MBP-SalA fusion protein, which was functional in vivo, to the sylA promoter. This may be due to experimental circumstances, or, alternatively, it may indicate that the activation is indirect via the activation of one or more additional transcription factors. The most likely candidates we considered were the $s y r F$ and syrG genes. Both encode HTH LuxR-type regulators, reside at the border of the large syringomycin/syringopeptin gene cluster, and were shown by microarray analysis to belong to the SalA regulon ( $\mathrm{Lu}$ et al. 2005). In addition, SyrF was shown to activate syr-syp genes and bind to an syrB1 promoter fragment, while SalA was necessary for $s y r F$ activity and bound to its promoter region (Wang et al. 2006). However, both the $s y r F$ and $s y r G$ mutants we generated showed wild-type behavior with regard to syringolin A production in planta and $s y l A$ and $s y l C$ reporter gene activity in vitro and, therefore, were ruled out as regulators of syringolin A biosynthesis. Because the microarray used by $\mathrm{Lu}$ and associates (2005) contained only 95 gene probes, the SalA regulon may well comprise additional unknown genes.

In wild-type bacteria, syringolin A accumulated to considerable amounts in conditioned $\mathrm{SRM}_{\mathrm{AF}}$ media only under still culture conditions, where lower cell densities are reached and oxygen availability is limited; therefore, we considered QS and oxygen concentration as possible negative regulators of syringolin A biosynthesis. However, an ahlI/ahlR deletion mutant exhibited a wild-type phenotype in both still and shaken cultures, indicating that these genes are not involved in syringolin A biosynthesis. Similarly, QS was reported not to be involved in the regulation of syringomycin biosynthesis (Dumenyo et al. 1998; Kinscherf and Willis 1999).

In contrast to the QS system, oxygen concentration seems to play a role in syringolin A biosynthesis, as evidenced by the fact that the sylC::lacZ reporter gene resulted in a two- to threefold higher $\beta$-gal activity in shaken cultures under oxygen-limiting conditions compared with well-aerated cultures. In $P$. aeruginosa, the Fnr-type oxygen sensor Anr is known to mediate the regulation of many pathways activated or repressed by low oxygen tension (Green et al. 2009; Trunk et al. 2010); therefore, we deleted the $a n r$ ortholog in P. syringae pv. syringae B301D-R. However, no significant effect of this deletion was detected, either on sylA::lacZ and sylC::lacZ reporter gene readouts under all culture conditions and upon infiltration 
into $N$. benthamiana, or on Pir7b transcript levels upon infiltration into rice leaves.

The potential of oxygen limitation as an inducer for the production of secondary metabolites by microbes in culture has long been recognized (Clark et al. 1995; Rollins et al. 1988). In the case of $P$. syringae pv. syringae, which is a leaf pathogen, the biological significance of the apparent oxygen sensitivity of syringolin A biosynthesis is not obvious. During the day, when stomates are open and photosynthesis takes place, oxygen is hardly limiting, even though the bacteria seem to form dense localized colonies (Fig. 4), which may develop biofilm-like properties. During the night, when stomata are closed and no photosynthesis occurs, this may be different. However, it is also possible that oxygen limitation in vitro activates a pathway leading to syringolin A biosynthesis which in planta is activated by other stimuli. Clearly, the picture obtained of the regulation of syringolin A biosynthesis remains incomplete. In order to identify additional genes involved, a more complete exploration of the salA regulon using $P$. syringae pv. syringae B728a whole-genome microarrays and the development of an efficient screening method for the identification of syringolin A-negative mutants would be helpful.

\section{MATERIALS AND METHODS}

Bacterial strains, plasmids, and media.

Bacterial strains and plasmids used in this study are listed in Table 3. Unless otherwise stated, bacteria were grown in LuriaBertani (LB) medium (tryptone at $10 \mathrm{~g} /$ liter, yeast extract at 5 $\mathrm{g} /$ liter, and $\mathrm{NaCl}$ at $10 \mathrm{~g} /$ liter) containing the appropriate antibiotics (ampicillin at $100 \mu \mathrm{g} / \mathrm{mg}$, gentamicin at $50 \mu \mathrm{g} / \mathrm{ml}$, kanamycin at $50 \mu \mathrm{g} / \mathrm{ml}$, or tetracycline at $10 \mu \mathrm{g} / \mathrm{ml}$ ) on a shaker at $28^{\circ} \mathrm{C}($ P. syringae pv. syringae $)$ or $37^{\circ} \mathrm{C}($ E. coli $)$.

\section{Syringolin A-inducing culture conditions.}

Cultures of $P$. syringae pv. syringae $(5 \mathrm{ml}$ each) were grown overnight in $\mathrm{SRM}_{\mathrm{AF}}$ medium (1\% D-glucose, $0.1 \% \mathrm{D}$-fructose, $100 \mu \mathrm{M}$ arbutin, $0.4 \%$ L-histidine, $0.8 \mathrm{mM} \mathrm{MgSO}_{4}, 10 \mu \mathrm{M}$ $\mathrm{FeCl}_{3}$, and $0.8 \mathrm{mM}$ potassium phosphate, $\mathrm{pH} 7$ ) (Gross and DeVay 1977; Mo and Gross 1991b) and tetracycline at 10 $\mu \mathrm{g} / \mathrm{ml}$, if appropriate, at $28^{\circ} \mathrm{C}$ on a shaker $(220 \mathrm{rpm} / \mathrm{min})$ overnight. The density was adjusted to $0.2 \mathrm{OD}_{600}$ and $1-\mathrm{ml}$ aliquots were used to inoculate $100-\mathrm{ml} \mathrm{SRM}_{\mathrm{AF}}$ cultures in $250-\mathrm{ml}$ Erlenmeyer flasks, which were incubated at $28^{\circ} \mathrm{C}$ for 5 to 7 days without shaking.

For low-oxygen condition experiments, 100-ml cultures were grown in 250-ml Erlenmeyer flasks on a shaker $(220 \mathrm{rpm})$ for $64 \mathrm{~h}$. Then, culture flasks were flushed with $\mathrm{N}_{2}$, the cap was removed, and the flask was sealed with parafilm to impede gas exchange. Cultures were then shaken for another $46 \mathrm{~h}$.

\section{Detection of syringolin A production.}

Syringolin A in conditioned media was detected by HPLC analysis, as described (Ramel et al. 2009). Syringolin A production by bacteria in planta was detected by infiltrating bacteria into leaves of 2- to 3-weak-old rice (Oryza sativa 'Loto') plants and analyzing accumulation of Pir $7 b$ transcripts by RNA gel blots $16 \mathrm{~h}$ after infiltration, as described (Ramel et al. 2009). Pir $7 b$ encodes an esterase (Wäspi et al. 1998b) whose corresponding transcript accumulates only upon infiltration of $P$. syringae pv. syringae producing syringolin A. Syringolin A was originally isolated based on Pir7b induction (Wäspi et al. 1998a).

\section{Extraction and analysis of RNA from bacteria.}

P. syringae pv. syringae B301D-R transformed with pOEAC was grown on a shaker in $50 \mathrm{ml}$ of $\mathrm{SRM}_{\mathrm{AF}}$ medium overnight at $28^{\circ} \mathrm{C}$. Bacteria were pelleted and resuspended in $1.6 \mathrm{ml}$ of cold trizol solution (38\% phenol, $0.8 \mathrm{M}$ guanidine thiocyanate, $0.4 \mathrm{M}$ ammonium thiocyanate, $0.1 \mathrm{M}$ sodium acetate, and $5 \%$ glycerol [vol/vol]). After centrifugation at $20,000 \times g$ for 10 min at $4^{\circ} \mathrm{C}$, the supernatant was recovered and vigorously shaken with $300 \mu \mathrm{l}$ of chloroform for $15 \mathrm{~min}$ at room temperature. After centrifugation for $8 \mathrm{~min}$ at $20,000 \times g$ at $4^{\circ} \mathrm{C}, 800$ $\mu \mathrm{l}$ of the supernatant was mixed with $400 \mu \mathrm{l}$ each of isopropanol and $0.8 \mathrm{M}$ sodium citrate $+1.2 \mathrm{M} \mathrm{NaCl}$ solution. The mixture was incubated at $-20^{\circ} \mathrm{C}$ overnight and RNA was pelleted by centrifugation for $8 \mathrm{~min}$ at $12,000 \times g$, washed with $75 \%$ ethanol, air dried, and dissolved in $60 \mu \mathrm{l}$ of diethylpyrocarbonate-treated water. RNA gel-blot analysis, ${ }^{32} \mathrm{P}$-labeling of probes, and hybridization were performed according to standard procedures (Ausubel et al. 1987). The probe fragments were amplified from $s y l C$ and $s y l E$ genes with primers sylC_N_f, sylC_N_r and sylE_N_f, sylE_N_r, respectively.

RT-PCR reactions with 1.5 to $2 \mu \mathrm{g}$ of total RNA were performed using the OneStep RT-PCR Kit (Qiagen, AG, Hombrechtikon, Switzerland) according to the manufacturer's protocol using primers RT_sylCD_f, RT_sylCD_r (for the sylC/ $s y l D$ intergenic region) and RT_sylDE_f, RT_sylDE_r (for the sylD/sylE intergenic region).

\section{Construction of mutants.}

Gene fragments of syrF (accession number AF372703; ORF position 59 to 889; fragment 127 to 802) and syrG (accession number AF372703; ORF position 6,136 to 6,924 ; fragment 6,249 to 6,827 ) were amplified with primer pairs syrF_KO_f/r and syrG_KO_f/r from genomic DNA of $P$. syringae pv. syringae $\mathrm{B} 301 \mathrm{D}-\mathrm{R}$ and cloned into the suicide vector pJQ200KS using the restriction sites BamHI and XhoI. Recombinant plasmids were transformed into E. coli S17-1 and mobilized into P. syringae pv. syringae B301D-R. Colonies carrying chromosomally integrated plasmids were selected for kanamycin resistance and plasmid insertions at the correct site were verified by PCR, as described (Amrein et al. 2004).

The construction of the markerless $\Delta$ sylA mutant has been described (Ramel et al. 2009). Markerless $\Delta$ ahlI/ahlR and $\Delta$ anr mutants in the $P$. syringae pv. syringae B301D-R background were constructed in an analogous way, whereby primers were designed according to the genome sequence of $P$. syringae pv. syringae B728a (accession number NC_007005.1, ahlI GeneID 3367123, ahlR GeneID 3367124, and anr GeneID 3368952 [Psyr_3425 ortholog]). In each case, flanking fragments were amplified using primer pairs $\mathrm{P} 1 / \mathrm{P} 2$ and $\mathrm{P} 3 / \mathrm{P} 4$, which were joined by overlap extension PCR using primer pair P1/P4. Mutants were verified by PCR using primers flanking the deleted sequences.

\section{Construction of promoter-reporter fusion genes.}

Syl promoter fragments were amplified by PCR from B301D-R genomic DNA. Primer sequences were designed according to the sequence of the syl gene cluster (accession number AJ548826). All promoter fragments were flanked by EcoRI and PstI sites and cloned into pME6014, resulting in translational fusions to the lac $Z$ gene named psylAp-lacZ, psylBp-lacZ, and psylCp-lacZ. The sylA-overexpressing sylA and $s y l B$ reporter plasmids pOEAA and pOEAB were constructed analogously to pOEAC, as described (Ramel et al. 2009). In short, the sylA ORF was put under the control of the lacZ promoter and placed onto the reporter plasmids psylAplacZ, psylBp-lacZ, and psylCp-lacZ, respectively, in opposite orientation. Similarly, the salA-overexpressing sylA (pOEsa1AA), $s y l B$ (pOEsalAB), and $s y l C$ (pOEsalAC) reporters were constructed by amplifying the salA ORF (accession number 
AF372703, position 7,960 to 8,829) from B301D-R genomic DNA using primers salA_OE_f and salA_OE_r. The PCR product was cloned into $\mathrm{pME} 6001^{\mathrm{k}}$ behind the $l a c Z$ promoter to yield pOESalA ${ }^{\mathrm{k}}$, from which the lacZp-salA fusion gene was amplified using primers SalA_OE_r and lacZp_OL_sylAp (or lacZp_OL_sylBp or lacZp_OL_sylCp, respectively). Then, the $s y l A$, $s y l B$, and $s y l C$ promoter fragments were amplified from psylAp_lacZ, psylBp_lacZ, and psylCp_lacZ, respectively, with the respective primer pairs syl[A/B/C]p_OL_ lacZp/syl [A/B/C]p_r. These fragments were joined to the corresponding lacZp-salA fusion fragments by overlap extension PCR with primer pairs salA_OE_r/syl[A/B/C]p_r, digested with EcoRI and PstI, and cloned into the polylinker of pME6014. All constructs were verified by sequencing.

\section{Quantitative $\beta$-gal assays.}

Quantitative $\beta$-gal assays were performed as described (Miller 1972) with some modifications. Samples of bacterial cultures were harvested from 72 to $168 \mathrm{~h}$ post inoculation (hpi) in intervals of approximately $24 \mathrm{~h}$. Z-buffer $(1 \mathrm{ml})(60 \mathrm{mM}$ $\mathrm{Na}_{2} \mathrm{HPO}_{4} \times 2 \mathrm{H}_{2} \mathrm{O}, 40 \mathrm{mM} \mathrm{NaH} \mathrm{PO}_{4} \times \mathrm{H}_{2} \mathrm{O}, 10 \mathrm{mM} \mathrm{KCl}, 1$ $\mathrm{mM} \mathrm{MgSO}{ }_{4} \times 7 \mathrm{H}_{2} \mathrm{O}$, and $50 \mathrm{mM} \beta$-mercaptoethanol), $20 \mu \mathrm{l}$ of $0.1 \%$ sodium dodecyl sulfate, $40 \mu \mathrm{l}$ of chloroform, and 100 to $300 \mu \mathrm{l}$ of bacterial culture were mixed by inversion. The suspension was centrifuged at $1,000 \times g$ for $5 \mathrm{~min}$. To $1 \mathrm{ml}$ of supernatant, $60 \mu \mathrm{l}$ of reagent solution $\left(60 \mathrm{mM} \mathrm{Na}_{2} \mathrm{HPO}_{4} \times\right.$ $2 \mathrm{H}_{2} \mathrm{O}, 40 \mathrm{mM} \mathrm{NaH} \mathrm{PO}_{4} \times \mathrm{H}_{2} \mathrm{O}$, and $1.4 \%$ [wt/vol] ortho-nitrophenyl- $\beta$-D-galactoside) was added. The reaction was stopped by adding $150 \mu \mathrm{l}$ of $1 \mathrm{M} \mathrm{Na}_{2} \mathrm{CO}_{3}$. Absorption was measured at $\mathrm{OD}_{420}$ and $\mathrm{MU}$ were calculated according to the formula $\mathrm{MU}=$ $1,000 \times \mathrm{OD}_{420} \times 1.21 / t \times V \times \mathrm{OD}_{600} \times 1.7$, where $t=$ reaction time in min and $V=$ volume of bacterial suspension added; the formula was adapted for the reagent volumes used here. Experiments were repeated independently two or three times, each with three to five replicate cultures. Data are usually shown as the average from the measurements at 96, 120, and $144 \mathrm{hpi}$, when values normally have reached a plateau.

\section{$\boldsymbol{\beta}$-gal assay in planta.}

Three-weak-old $N$. benthamiana plants grown at $25^{\circ} \mathrm{C}$ in a greenhouse under a regime of $16 \mathrm{~h}$ of light and $8 \mathrm{~h}$ of darkness were infiltrated with a suspension of bacteria transformed with reporter constructs at an $\mathrm{OD}_{600}$ of 0.0002 (approximately $10^{5}$ bacteria/ml) using a syringe without a needle. Leaves were harvested after 72 to 96 hpi. Leaf disks $(1 \mathrm{~cm})$ were punched out from infiltrated areas and vacuum infiltrated with $1 \%$ glutaraldehyde in potassium phosphate buffer $\left(0.2 \mathrm{M} \mathrm{NaPO}_{4}, \mathrm{pH}\right.$ 7 ) to inactivate the endogenous $\beta$-gal of the plants (Teeri et al. 1989). Leaf disks were washed three times in potassium phosphate buffer and incubated overnight with $1 \mathrm{mM}$ 5-bromo-4chloro-3-indolyl-beta-D-galactopyranoside. Stained disks were washed once in potassium phosphate buffer and incubated in acetone/methanol (1:3) for $3 \mathrm{~h}$ at $37^{\circ} \mathrm{C}$ to remove chlorophyll. After a final wash in $100 \%$ ethanol, leaf disks were arranged on glass slides in $50 \%$ glycerol for observation under the light microscope.

\section{MBP-SylA and MBP-SalA fusion proteins.}

SylA and salA genes were amplified by PCR using primer pairs sylAFP_f/r and salAFP_f/r, respectively, and cloned into the vectors pMal-c2X and pMEKm12 to yield pMalSylA and pMEKmSylA for expression in E. coli and P. syringae

Table 3. Bacterial strains and plasmids

\begin{tabular}{|c|c|c|}
\hline Strains & Genotype, relevant characteristics & Reference \\
\hline \multicolumn{3}{|l|}{ Escherichia coli } \\
\hline DH10B & $F^{-}$endA1 recA1 galE15 galK16 nupG rpsL $\triangle 1$ lacX74 $\$ 80 l a c Z 4 M 15$ araD139 & \\
\hline & $\Delta($ ara,leu $) 7697$ mcrA $\Delta(m r r-h s d R M S-m c r B C) \lambda^{-}$ & Grant et al. 1990 \\
\hline XL1-Blue & $\begin{array}{l}\text { endA1 gyrA96 }\left(\text { nal }^{\mathrm{r}}\right) \text { thi-1 recA1 relA1 lac glnV44 } F^{\prime}\left[: \because \text { Tn10 proAB }{ }^{+} \text {lacI }{ }^{\mathrm{q}} \Delta(\text { lacZ)M15] }\right. \\
\text { hsdR17 }\left({r_{K}^{-}}^{-} \mathrm{m}_{K}^{+}\right)\end{array}$ & Bullock et al. 1987 \\
\hline S17-1 & $\begin{array}{l}\text { (thi pro hsdR recA; chromosomal RP4 }\left[\mathrm{Tra}^{+} \mathrm{Tc}^{\mathrm{s}} \mathrm{Km}^{\mathrm{s}} \mathrm{Ap} \mathrm{p}^{\mathrm{s}}\right] \text { ); used as donor strain in } \\
\text { biparental matings }\end{array}$ & Simon et al. 1983 \\
\hline \multicolumn{3}{|c|}{ Pseudomonas syringae pv. syringae } \\
\hline B301D-R & Wild type, isolated from pear, Rif $^{\mathrm{r}}$ & $\mathrm{Xu}$ and Gross 1988 \\
\hline DSL7 & salA::nptII insertion mutant in B301D-R, $\mathrm{Kan}^{\mathrm{r}}$ & Lu et al. $2002 \mathrm{a}$ \\
\hline$\Delta$ sylA & sylA deletion mutant in B301D-R & Ramel et al. 2009 \\
\hline SyrF_KO & syrF plasmid insertion mutant in B301D-R, Tet $^{\mathrm{r}}$ & This study \\
\hline SyrG_KO & syrG plasmid insertion mutant in B301D-R, $\mathrm{Gm}^{\mathrm{r}}$ & This study \\
\hline$\Delta$ ahlI/ahlR & ahlI/ahlR (quorum sensing system) double deletion mutant in B301D-R & This study \\
\hline$\Delta$ anr & $\begin{array}{l}\text { Anr homologue deletion mutant in B301D-R (ortholog of Psyr_3425 of } \\
\text { P. syringae pv. syringae B728a) }\end{array}$ & This study \\
\hline \multicolumn{3}{|c|}{ 20. } \\
\hline pMal-c2x & $\begin{array}{l}\text { Commercial } E . \text { coli overexpression vector, designed to produce maltose-binding protein } \\
\text { fusions, } \mathrm{Amp}^{\mathrm{r}}\end{array}$ & New England Biolabs \\
\hline pMEKm12 & P. syringae pv. syringae overexpression vector, derivative of pMal-c2x. Amp ${ }^{\mathrm{r}}, \mathrm{Kan}^{\mathrm{r}}$ & Lu et al. $2002 b$ \\
\hline pME3087 & Suicide vector, ColE1 replicon, Tet $^{\mathrm{r}}$ & Voisard et al. 1994 \\
\hline pJQ200KS & Suicide vector, p15A ori, $\mathrm{Gm}^{\mathrm{r}}$ & Quandt and Hynes, 1993 \\
\hline pME6014 & $L a c Z$ reporter plasmid, used for quantitative promoter activity measurements, $\operatorname{Tet}^{\mathrm{r}}$ & Schnider-Keel et al. 2000 \\
\hline psylAp_lacZ & sylA promoter translationally fused to the $l a c Z$ gene of pME6014, Tet $^{\mathrm{r}}$ & This study \\
\hline psylBp_lacZ & sylB promoter translationally fused to the $l a c Z$ gene of $\mathrm{pME6014}, \mathrm{Tet}^{\mathrm{r}}$ & This study \\
\hline psylCp_lacZ & sylC promoter translationally fused to the $l a c Z$ gene of $\mathrm{pME6014}, \mathrm{Tet}^{\mathrm{r}}$ & This study \\
\hline pME6001 & P. syringae pv. syringae overexpression vector, $\mathrm{Gm}^{\mathrm{r}}$ & Blumer et al. 1999 \\
\hline pOEA $^{\mathrm{K}}$ & pME6001 derivative, overexpressing sylA, $\mathrm{Gm}^{\mathrm{r}}, \mathrm{Kan}^{\mathrm{r}}$ & Ramel et al. 2009 \\
\hline OEsalA ${ }^{\mathrm{K}}$ & pME6001 derivative, overexpressing salA, $\mathrm{Gm}^{\mathrm{r}}, \mathrm{Kan}^{\mathrm{r}}$ & This study \\
\hline pOEAC & pME6014 derivative containing a lacZp::sylA gene and the sylCp::lacZ reporter gene, Tet ${ }^{\mathrm{r}}$ & Ramel et al. 2009 \\
\hline pOEAA & pME6014 derivative containing a lacZp::sylA gene and the sylAp::lacZ reporter gene, Tet ${ }^{\mathrm{r}}$ & This study \\
\hline pOEAB & pME6014 derivative containing a lacZp::sylA gene and the sylBp::lacZ reporter gene, Tet $^{\mathrm{r}}$ & This study \\
\hline pOEsalAAp & pME6014 derivative containing a lacZp::salA gene and the sylAp::lacZ reporter gene, Tet ${ }^{\mathrm{r}}$ & This study \\
\hline pOEsalABp & pME6014 derivative containing a lacZp::salA gene and the sylBp::lacZ reporter gene, Tet ${ }^{\mathrm{r}}$ & This study \\
\hline pOEsalACp & pME6014 derivative containing a lacZp::salA gene and the sylCp::lacZ reporter gene, Tet $^{\mathrm{r}}$ & This study \\
\hline
\end{tabular}

${ }^{\mathrm{a}} \mathrm{Rif}^{\mathrm{r}}, \mathrm{Kan}^{\mathrm{r}}, \mathrm{Tet}^{\mathrm{r}}, \mathrm{Gm}^{\mathrm{r}}$, and $\mathrm{Amp}^{\mathrm{r}}$ indicate resistance to rifampicin, kanamycin, tetracyclin, gentamicin, and ampicillin, respectively. 
pv. syringae B301D-R, respectively. After verification by sequencing, they were transformed into $E$. coli $\mathrm{DH} 10 \mathrm{~B}$ and $P$. syringae pv. syringae B301D-R. Bacterial cultures $(3 \times 200$ $\mathrm{ml})$ in LB with the appropriate antibiotic were grown to an $\mathrm{OD}_{600}$ of 0.5 to 1 before expression of the fusion gene was induced by the addition of isopropyl- $\beta$-D-thiogalactopyranoside to a final concentration of $0.3 \mathrm{mM}$ for $E$. coli and 5 $\mathrm{mM}$ for $P$. syringae pv. syringae. Cultures were further incubated for 5 and $7 \mathrm{~h}$ (E. coli and $P$. syringae pv. syringae, respectively) before bacteria were pelleted by centrifugation $\left(4,000 \times \mathrm{g}, 20 \mathrm{~min}, 4^{\circ} \mathrm{C}\right)$ and resuspended in a total of 22.5 $\mathrm{ml}$ of binding buffer $(20 \mathrm{mM}$ Tris- $\mathrm{HCl}$ [pH 7.5], $100 \mathrm{mM}$ $\mathrm{NaCl}, 1 \mathrm{mM}$ EDTA, $1 \mathrm{mM}$ dithiothreitol, $10 \%$ glycerol, and $0.01 \%$ Triton $\mathrm{X}-100)$. The suspension was supplemented with protease inhibitors (one tablet per $10 \mathrm{ml}$ of Complete Mini Protease Inhibitor Cocktail; Roche Applied Science, Rotkreuz, Switzerland). Cells were broken with a French press and cell debris was removed by centrifugation $(10,000 \times g$, $30 \mathrm{~min}, 4^{\circ} \mathrm{C}$ ). The protein concentration in the supernatant was estimated by measuring the absorption at $280 \mathrm{~nm}$. On average, extracts contained protein at approximately 35 $\mathrm{mg} / \mathrm{ml}$ (E. coli) and $25 \mathrm{mg} / \mathrm{ml}$ (P. syringae pv. syringae). To verify the correct size of fusion proteins (MBP-SylA, $69 \mathrm{kDa}$; MBP-SalA, $74 \mathrm{kDa}$; and MBP, $51 \mathrm{kDa}$ ), protein extracts were analyzed on protein gel blots using an anti-MBP antibody (New England Biolabs, Ipswich, MA, U.S.A.) according to standard procedures (Ausubel et al. 1987).

\section{MDAE.}

MDAE was carried out with minor modifications as described (Koebnik et al. 2006). To amplify biotinylated promoter probes, biotinylated primers were used. Purified biotinylated DNA (10 pmol) in $200 \mu \mathrm{l}$ of $\mathrm{H}_{2} \mathrm{O}$ was added to an equal volume of magnetic beads (Dynabeads; Invitrogen, San Diego, CA, U.S.A.) suspension prepared as described (Koebnik et al. 2006). The suspension was incubated with slight agitation for $2 \mathrm{~h}$ at room temperature, washed three times for $5 \mathrm{~min}$ with wash buffer (10 mM Tris- $\mathrm{HCl}[\mathrm{pH} 7.5]$ and $2 \mathrm{M} \mathrm{NaCl}$ ), and resuspended in $1.1 \mathrm{ml}$ of binding buffer $(20 \mathrm{mM}$ Tris- $\mathrm{HCl}[\mathrm{pH}$ 7.5], $100 \mathrm{mM} \mathrm{NaCl}, 1 \mathrm{mM}$ EDTA, $1 \mathrm{mM}$ dithiothreitol, $10 \%$ glycerol, and $0.01 \%$ Triton X-100) containing $18 \mathrm{mM}$ maltose and a 10-fold (wt/wt) excess of salmon sperm DNA (SigmaAldrich, Buchs, Switzerland) over fragment DNA. Finally, the suspension was mixed with $900 \mu \mathrm{l}$ of whole protein extract from $P$. syringae pv. syringae B301D-R or E. coli overexpressing MBP, MBP-SylA, or MBP-SalA protein. The mixture was gently agitated for $45 \mathrm{~min}$ at room temperature. Beads were then washed with binding buffer (three times, $5 \mathrm{~min}$; in the second wash step, competitor DNA was added) and proteins were eluted twice with $100 \mu \mathrm{l}$ of elution buffer $(20 \mathrm{mM}$ Tris- $\mathrm{HCl}$ [pH 7.5], $2 \mathrm{M} \mathrm{NaCl}, 1 \mathrm{mM}$ EDTA, $1 \mathrm{mM}$ dithiothreitol, 10\% glycerol, and $0.01 \%$ Triton $\mathrm{X}-100)$. The two eluates were combined and concentrated to approximately $40 \mu \mathrm{l}$ using $\mathrm{Vi}$ vaspin 500 (MWOC 10,000; Sartorius AG, Göttingen, Germany). Proteins were subjected to gel-blot analysis using antiMBP antibody according to standard procedures (Ausubel et al. 1987).

\section{ACKNOWLEDGMENTS}

We thank C. Reimmann, D. Haas, and D. C. Gross for strains and vectors; and Z. Hasenkamp for technical assistance. C. Ramel planned and performed most of the experiments. N. Baechler, M. Meyer, M. Hildbrand, and D. Schädeli were involved in the construction of some mutants and some $\beta$-gal assays. C. Ramel and R. Dudler designed research and wrote the article. Financial support from the Swiss National Science Foundation (grants 3100A0-115970 and 31003A-134936) and the University of Zurich is gratefully acknowledged.

\section{LITERATURE CITED}

Amrein, H., Makart, S., Granado, J., Shakya, R., Schneider-Pokorny, J., and Dudler, R. 2004. Functional analysis of genes involved in the synthesis of syringolin A by Pseudomonas syringae pv. syringae B301D-R. Mol. Plant-Microbe Interact. 17:90-97.

Ausubel, F. M., Brent, R., Kingston, R. E., Moore, D. D., Smith, J. A., Seidman, J. G., and Struhl, K. 1987. Current Protocols in Molecular Biology. Wiley and Sons, New York.

Bauer, C. E., Elsen, S., and Bird, T. H. 1999. Mechanisms for redox control of gene expression. Annu. Rev. Microbiol. 53:495-523.

Blumer, C., and Haas, D. 2000. Mechanism, regulation, and ecological role of bacterial cyanide biosynthesis. Arch. Microbiol. 173:170-177.

Blumer, C., Heeb, S., Pessi, G., and Haas, D. 1999. Global GacA-steered control of cyanide and exoprotease production in Pseudomonas fluorescens involves specific ribosome binding sites. Proc. Natl. Acad. Sci. U.S.A. 96:14073-14078.

Bullock, W. O., Fernandez, J. M., and Short, J. M. 1987. XL1-Blue-A high-efficiency plasmid transforming recA Escherichia coli strain with beta-galactosidase selection. Biotechniques 5:376.

Chatterjee, A., Cui, Y. Y., Yang, H. L., Collmer, A., Alfano, J. R., and Chatterjee, A. K. 2003. GacA, the response regulator of a two-component system, acts as a master regulator in Pseudomonas syringae pv. tomato DC3000 by controlling regulatory RNA, transcriptional activators, and alternate sigma factors. Mol. Plant-Microbe Interact. 16:1106-1117.

Clark, G. J., Langley, D., and Bushell, M. E. 1995. Oxygen limitation can induce microbial secondary metabolite formation-investigations with miniature electrodes in shaker and bioreactor culture. Microbiol. UK 141:663-669.

Dillon, S. C., and Dorman, C. J. 2010. Bacterial nucleoid-associated proteins, nucleoid structure and gene expression. Nat. Rev. Microbiol. 8:185-195.

Dumenyo, C. K., Mukherjee, A., Chun, W., and Chatterjee, A. K. 1998. Genetic and physiological evidence for the production of $\mathrm{N}$-acyl homoserine lactones by Pseudomonas syringae pv. syringae and other fluorescent plant pathogenic Pseudomonas species. Eur. J. Plant Pathol. 104:569-582.

Grant, S. G. N., Jessee, J., Bloom, F. R., and Hanahan, D. 1990. Differential plasmid rescue from transgenic mouse DNAs into Escherichia coli methylation-restriction mutants. Proc. Natl. Acad. Sci. U.S.A. 87:46454649.

Green, J., Crack, J. C., Thomson, A. J., and LeBrun, N. E. 2009. Bacterial sensors of oxygen. Curr. Opin. Microbiol. 12:145-151.

Groll, M., Schellenberg, B., Bachmann, A. S., Archer, C. R., Huber, R., Powell, T. K., Lindow, S., Kaiser, M., and Dudler, R. 2008. A plant pathogen virulence factor inhibits the eukaryotic proteasome by a novel mechanism. Nature 452:755-758.

Gross, D. C. 1985. Regulation of syringomycin synthesis in Pseudomonas syringae pv. syringae and defined conditions for its production. J. Appl. Bacteriol. 58:167-174.

Gross, D. C., and DeVay, J. E. 1977. Role of syringomycin in holcus spot of maize and systemic necrosis of cowpea caused by Pseudomonas syringae. Physiol. Plant Pathol. 11:1-11.

Hassa, P., Granado, J., Freydl, E., Waspi, U., and Dudler, R. 2000. Syringolin-mediated activation of the Pir7b esterase gene in rice cells is suppressed by phosphatase inhibitors. Mol. Plant-Microbe Interact. 13:342346.

Heeb, S., and Haas, D. 2001. Regulatory roles of the GacS/GacA twocomponent system in plant-associated and other gram-negative bacteria. Mol. Plant-Microbe Interact. 14:1351-1363.

Hirano, S. S., and Upper, C. D. 2000. Bacteria in the leaf ecosystem with emphasis on Pseudomonas syringae-A pathogen, ice nucleus, and epiphyte. Microbiol. Mol. Biol. Rev. 64:624.

Hirano, S. S., Ostertag, E. M., Savage, S. A., Baker, L. S., Willis, D. K., and Upper, C. D. 1997. Contribution of the regulatory gene lemA to field fitness of Pseudomonas syringae pv. syringae. Appl. Environ. Microbiol. 63:4304-4312.

Hrabak, E. M., and Willis, D. K. 1992. The lemA gene required for pathogenicity of Pseudomonas syringae pv. syringae on bean is a member of a family of two-component regulators. J. Bacteriol. 174:3011-3020.

Hrabak, E. M., and Willis, D. K. 1993. Involvement of the lemA gene in production of syringomycin and protease by Pseudomonas syringae pv. syringae. Mol. Plant-Microbe Interact. 6:368-375.

Hull, G., Garrido, J. M. G., Parcy, F., Menossi, M., MartinezIzquierdo, J. A., and Gallois, P. 1996. Use of the lacZ reporter gene as an internal control for GUS activity in microprojectile bombarded plant tissue. Plant Sci. 120:153-160.

Huo, Y. X., Zhang, Y. T., Xiao, Y., Zhang, X. D., Buck, M., Kolb, A., and Wang, Y. P. 2009. IHF-binding sites inhibit DNA loop formation and transcription initiation. Nucleic Acids Res. 37:3878-3886. 
Imker, H. J., Walsh, C. T., and Wuest, W. M. 2009. SylC catalyzes ureidobond formation during biosynthesis of the proteasome inhibitor syringolin A. J. Am. Chem. Soc. 131:18263.

Kinscherf, T. G., and Willis, D. K. 1999. Swarming by Pseudomonas syringae $\mathrm{B} 728$ a requires gacS (lemA) and gacA but not the acyl-homoserine lactone biosynthetic gene ahlI. J. Bacteriol. 181:4133-4136.

Kitten, T., Kinscherf, T. G., McEvoy, J. L., and Willis, D. K. 1998. A newly identified regulator is required for virulence and toxin production in Pseudomonas syringae. Mol. Microbiol. 28:917-929.

Koebnik, R., Kruger, A., Thieme, F., Urban, A., and Bonas, U. 2006. Specific binding of the Xanthomonas campestris pv. vesicatoria AraC-type transcriptional activator $\mathrm{HrpX}$ to plant-inducible promoter boxes. J. Bacteriol. 188:7652-7660.

Lu, S. E., Scholz-Schroeder, B. K., and Gross, D. C. 2002a. Characterization of the $s a l A, s y r F$, and $s y r G$ regulatory genes located at the right border of the syringomycin gene cluster of Pseudomonas syringae pv. syringae. Mol. Plant-Microbe Interact. 15:43-53.

Lu, S. E., Scholz-Schroeder, B. K., and Gross, D. C. 2002b. Construction of pMEKm12, an expression vector for protein production in Pseudomonas syringae. FEMS (Fed. Eur. Microbiol. Soc.) Microbiol. Lett. 210:115-121

Lu, S. E., Wang, N., Wang, J. L., Chen, Z. J., and Gross, D. C. 2005. Oligonucleotide microarray analysis of the salA regulon controlling phytotoxin production by Pseudomonas syringae pv. syringae. Mol. PlantMicrobe Interact. 18:324-333.

Macchi, R., Montesissa, L., Murakami, K., Ishihama, A., de Lorenzo, V., and Bertoni, G. 2003. Recruitment of $\sigma^{54}$-RNA polymerase to the $P u$ promoter of Pseudomonas putida through integration host factor-mediated positioning switch of $\alpha$ subunit carboxyl-terminal domain on an UP-like element. J. Biol. Chem. 278:27695-27702.

Melville, S. B., and Gunsalus, R. P. 1996. Isolation of an oxygen-sensitive FNR protein of Escherichia coli: Interaction at activator and repressor sites of FNR-controlled genes. Proc. Natl. Acad. Sci. U.S.A. 93:12261231 .

Michel, K., Abderhalden, O., Bruggmann, R., and Dudler, R. 2006. Transcriptional changes in powdery mildew infected wheat and Arabidopsis leaves undergoing syringolin-triggered hypersensitive cell death at infection sites. Plant Mol. Biol. 62:561-578.

Miller, J. H. 1972. Experiments in Molecular Genetics. Cold Spring Harbor Laboratory Press, Cold Spring Harbor, NY, U.S.A.

Mo, Y. Y., and Gross, D. C. 1991a. Expression in vitro and during plant pathogenesis of the $s y r B$ gene required for syringomycin production by Pseudomonas syringae pathovar syringae. Mol. Plant-Microbe Interact. 4:28-36.

Mo, Y.-Y., and Gross, D. C. 1991b. Plant signal molecules activate the $s y r B$ gene, which is required for syringomycin production by Pseudomonas syringae pv. syringae. J. Bacteriol. 173:5784-5792.

Munch, R., Hiller, K., Grote, A., Scheer, M., Klein, J., Schobert, M., and Jahn, D. 2005. Virtual footprint and PRODORIC: An integrative framework for regulon prediction in prokaryotes. Bioinformatics 21:41874189.

Quandt, J., and Hynes, M. F. 1993. Versatile suicide vectors which allow direct selection for gene replacement in gram-negative bacteria. Gene 127:15-21.

Quinones, B., Pujol, C. J., and Lindow, S. E. 2004. Regulation of AHL production and its contribution to epiphytic fitness in Pseudomonas syringae. Mol. Plant-Microbe Interact. 17:521-531.

Ramel, C., Tobler, M., Meyer, M., Bigler, L., Ebert, M. O., Schellenberg, B., and Dudler, R. 2009. Biosynthesis of the proteasome inhibitor syringolin A: The ureido group joining two amino acids originates from bicarbonate. BMC Biochem. 10:26.

Reimmann, C., Hofmann, C., Mauch, F., and Dudler, R. 1995. Characterization of a rice gene induced by Pseudomonas syringae pv. syringae: Requirement for the bacterial lemA gene function. Physiol. Mol. Plant Pathol. 46:71-81

Rich, J. J., Hirano, S. S., and Willis, D. K. 1992. Pathovar-specific requirement for the Pseudomonas syringae lemA gene in disease lesion for- mation. Appl. Environ. Microbiol. 58:1440-1446.

Rich, J. J., Kinscherf, T. G., Kitten, T., and Willis, D. K. 1994. Genetic evidence that the gacA gene encodes the cognate response regulator for the lemA sensor in Pseudomonas syringae. J. Bacteriol. 176:7468-7475.

Rollins, M. J., Jensen, S. E., and Westlake, D. W. S. 1988. Effect of aeration on antibiotic production by Streptomyces clavuligerus. J. Ind. Microbiol. 3:357-364.

Sawers, G. 1999. The aerobic/anaerobic interface. Curr. Opin. Microbiol 2:181-187.

Schellenberg, B., Ramel, C., and Dudler, R. 2010. Pseudomonas syringae virulence factor syringolin A counteracts stomatal immunity by proteasome inhibition. Mol. Plant-Microbe Interact. 23:1287-1293.

Schnider-Keel, U., Seematter, A., Maurhofer, M., Blumer, C., Duffy, B., Gigot-Bonnefoy, C., Reimmann, C., Notz, R., Defago, G., Haas, D., and Keel, C. 2000. Autoinduction of 2,4-diacetylphloroglucinol biosynthesis in the biocontrol agent Pseudomonas fluorescens $\mathrm{CHA} 0$ and repression by the bacterial metabolites salicylate and pyoluteorin. J. Bacteriol. 182:1215-1225.

Simon, R., Priefer, U., and Puhler, A. 1983. A broad host range mobilization system for in vivo genetic engineering: Transposon mutagenesis in gram-negative bacteria. Bio-Technology 1:784-791.

Teeri, T. H., Lehvaslaiho, H., Franck, M., Uotila, J., Heino, P., Palva, E. T., Vanmontagu, M., and Herreraestrella, L. 1989. Gene Fusions to LacZ reveal new expression patterns of chimeric genes in transgenic plants. EMBO (Eur. Mol. Biol. Organ.) J. 8:343-350.

Trunk, K., Benkert, B., Quack, N., Munch, R., Scheer, M., Garbe, J., Jansch, L., Trost, M., Wehland, J., Buer, J., Jahn, M., Schobert, M., and Jahn, D. 2010. Anaerobic adaptation in Pseudomonas aeruginosa: Definition of the Anr and Dnr regulons. Environ. Microbiol. 12:1719-1733.

Voisard, C., Bull, C. T., Keel, C., Laville, J., Maurhofer, M., Schnider, U. Défago, G., and Haas, D. 1994. Biocontrol of root diseases by Pseudomonas fluorescens CHA0: Current concepts and experimental approaches. Pages 67-89 in: Molecular Ecology of Rhizosphere Microorganisms. F. O'Gara, F. D. N. Dowling, and B. Boesten, eds. VCH Publishers, Weinheim, Germany.

Wang, N., Lu, S. E., Records, A. R., and Gross, D. C. 2006. Characterization of the transcriptional activators SalA and SyrF, which are required for syringomycin and syringopeptin production by Pseudomonas syringae pv. syringae. J. Bacteriol. 188:3290-3298.

Wäspi, U., Blanc, D., Winkler, T., Ruedi, P., and Dudler, R. 1998a. Syringolin, a novel peptide elicitor from Pseudomonas syringae pv. syringae that induces resistance to Pyricularia oryzae in rice. Mol. PlantMicrobe Interact. 11:727-733.

Wäspi, U., Misteli, B., Hasslacher, M., Jandrositz, A., Kohlwein, S. D., Schwab, H., and Dudler, R. 1998b. The defense-related rice gene Pir $7 b$ encodes an "alpha/beta hydrolase fold" protein exhibiting esterase activity towards naphthol AS-esters. Eur. J. Biochem. 254:32-37.

Wäspi, U., Hassa, P., Staempfli, A., Molleyres, L.-P., Winkler, T., and Dudler, R. 1999. Identification and structure of a family of syringolin variants: Unusual cyclic peptides from Pseudomonas syringae pv. syringae that elicit defense responses in rice. Microbiol. Res. 154:1-5.

Wäspi, U., Schweizer, P., and Dudler, R. 2001. Syringolin reprograms wheat to undergo hypersensitive cell death in a compatible interaction with powdery mildew. Plant Cell 13:153-161.

Willis, D. K., Hrabak, E. M., Rich, J. J., Barta, T. M., Lindow, S. E., and Panopoulos, N. J. 1990. Isolation and characterization of a Pseudomonas syringae pathovar syringae mutant deficient in lesion formation on bean. Mol. Plant-Microbe Interact. 3:149-156.

$\mathrm{Xu}, \mathrm{G}$. W., and Gross, D. C. 1988. Physical and functional analyses of the syrA and syrB genes involved in syringomycin production by Pseudomonas syringae pv. syringae. J. Bacteriol. 170:5680-5688.

\section{AUTHOR-RECOMMENDED INTERNET RESOURCES}

Virtual Footprint software suite: prodoric.tu-bs.de/vfp

Prodoric database: www.prodoric.de/matrix.php?matrix_acc=MX000011 